\title{
Mixed Methods in Public Health Research
}

\author{
Deepak Paudel \\ BPH, MPH, MPA \\ paudeld@gmail.com
}

\section{What is mixed methods research?}

Mixed methods are becoming more popular in public health research and being used by the researcher in different ways. Mixed methods generally mean use of multiple methods of data collection with an aim to produce high-quality data by validating information collected from one source by other and by compensating weakness or gaps of a method by another.

Mixed methods research is defined as a "methodology for conducting research that involves collecting, analyzing, and integrating (or mixing) quantitative and qualitative research (and data) in a single study or a longitudinal program of inquiry". The purpose of this form of research is that both qualitative and quantitative research, in combination, provide a better understanding of a research problem or issue than either research approach alone. (Creswell, JW.)

\section{Mixed Methods Research: State of the Art}

\section{Quantitative Data}

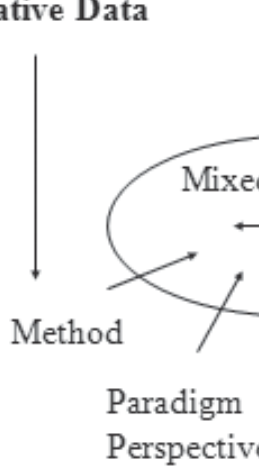

Source: Creswell, JW.

\section{Why mixed methods?}

Any research generally adopts multiple methods of data collection with an aim to improve reliability and validity of the information collection. All data collection approaches has some strengths and limitations, thus to overcome the limitations of the specific methods, other approaches are adopted to validate and triangulate the information. Mixed methods also helps to minimize bias due to measurement error, such as instrumental error, interviewer error or interpretation error.

Data on health research are classified as "quantitative" and "qualitative" data. Quantitative data are collected from surveys, structured interviews, and observation using structured questionnaire or checklist, whereas the qualitative data are collected from in-depth interview, focus group discussions and participatory approaches using unstructured or semi-structured guideline. Quantitative surveys provide answers of "what" or "how much" questions such as estimates of coverage (e.g. \% of population reached with the immunization program) or magnitudes of problems (e.g. prevalence of pneumonia among under-five children), whereas the qualitative methods provide answers of "why" questions related to causes, consequences and reasons (e.g. Why health care utilization is lower among marginalized population). As most of our research questions do not end on either "what" or "why" aspects, using mixed methods are recommended. For example, if you are interested knowing the magnitude of pneumonia in a specific population; you may get that answer by a quantitative survey, then the immediate next question that you will come to your mind are: "Why this is higher among a group than the other group?" or "Why they don't go to health center when they are sick?" and so on. Thus, mixed methods will help the researcher to understand the wider picture of the research problem.

\section{How to balance the methods?}

Using multiple methods is always good to get more information, but not always feasible and appropriate. Thus, a researcher should always use their judgments about the right balance of information based on the nature and importance of their research question, availability of funds and other resources to carryout research, and relative utility of the data. The data collected should always be within the "manageable interest" of the researcher. In short, there is no set formula for deciding balance between different methods, but will be guided by various factors mentioned here.

\section{Is mixed methods always better?}

Not really! It depends on what you want to investigate, what is your main research question(s), and what value the additional method is going to add in the data quality. More does not always mean better. It should be a conscious effort to use additional method to fill-in the gap of the main method. If you just want to know "How many people are currently using family planning contraceptives?" then a quantitative survey is good enough. If you want to know "Why women are not exclusively breastfeeding their child?" some FGDs 
are good enough. Thus, you always have to be clear on "What you want?", "What you are going to get using minimum tools/methods?" and "What you might need to fill the gaps?" In summary, carefully designed mixed methods generally yield better results than a single method research, but it depends on lot of other factors.

\section{Why mixed methods are important for public health students?}

Public health is a broad discipline interfacing with medicine, social science, management and others. Issues in health care services are multi-facet. Health problems and diseases are outcomes of multiple causes. Thus, the cause-effect analysis, attribution and contributions, impact and outcomes can not be explained with data analysis using a single method. Mixed methods are not always adequate but generally preferred over single methods. As a public health student sometime in your career, you all will encounter different types of research questions or a complex research question requiring use of mixed methods for your research. Thus, mixed methods research is going to help you to understand importance and utility of different research methods.

\section{References}

1. Axinn, WG. Pearce, LD. Mixed method data collection strategies. Cambridge University Press. 2006.

2. O'Cathai, A. Editorial - Mixed Methods Research in the Health Sciences: A Quiet Revolution. Journal of Mixed Methods Research. Volume 3 Number 1, January 2009 3-6. [Accessed on August 18, 2011 from http:// mmr.sagepub.com/content/3/1/3.full.pdf]

3. Mixed Methods for Health Research - Overview of mixed methods research design \& review [Accessed on August 18, 2011 from http://www2.warwick.ac.uk/fac/ $\mathrm{med} / \mathrm{research} / \mathrm{hsri} / \mathrm{primary}$ _care/research_/ centrepatexp/complexityhealth/mixedmethods/

4. Creswell, JW. Mixed Methods Research: State of the Art (What Has Developed In Mixed Methods)[Accessed on August 18, 2011 from http:// sitemaker.umich.edu/creswell.workshop/ power_point_slides_for_lecture]

5. Last, JM. (ed.) A dictionary of Epidemiology. International Epidemiological Association. 2008. 